\title{
Management of axilla in breast cancer: the past, present and the future
}

\author{
Oshan Basnayake ${ }^{1}$, Umesh Jayarajah ${ }^{1}$, Sanjeewa Seneviratne ${ }^{2}$ \\ ${ }^{1}$ Professorial Surgical Unit, National Hospital of Sri Lanka, Colombo, Sri Lanka \\ ${ }^{2}$ Department of Surgery, Faculty of Medicine, University of Colombo, Sri Lanka
}

Keywords: Breast cancer; sentinel lymph node; axillary lymph node dissection; neoadjuvant chemotherapy

\begin{abstract}
The role of surgery in treatment of breast cancer has evolved substantially during the last century where radical surgery has gradually been replaced by more conservative approaches. Similarly, surgical treatment of the axilla has changed rapidly especially over last three decades. This is mostly as a result of improvements in understanding of disease behaviour and advances in systemic therapy. Axillary surgery has the dual uses of removing the disease from the axilla and providing information for prognostication which help guide adjuvant therapy. However, surgery to the axilla is associated with substantial morbidly including lymphedema and shoulder stiffness. Hence, less radical approaches for the treatment of the axilla have been of interest.
\end{abstract}

The traditional gold standard of axillary lymph node dissection was challenged by many clinical trials. As result sentinel lymph node biopsy was introduced as an alternative for patients with clinically negative axillae which later became the standard of care for such patients. Subsequent studies proved the safety of omitting completion axillary dissection or replacing with radiotherapy for selected patients with minimal sentinel lymph node involvement.

The application of sentinel lymph node biopsy for axillary staging after neoadjuvant chemotherapy has become an area of clinical interest. However, sentinel lymph node biopsy in node-positive patients who become node negative after neoadjuvant chemotherapy is controversial at present due to the relatively high false-negative rate. This however, is improved by careful patient selection combined with some minor changes to the surgical technique of sentinel lymph node biopsy.

Correspondence: Sanjeewa Seneviratne

E-mail: sanjeewa@srg.cmb.ac.lk

Received: 14-12-2017 Accepted: 26-12-2018

(iD) http://orcid.org/0000-0003-0310-1387

DOI: http://doi.org/10.4038/sljs.v36i4.8555

The Sri Lanka Journal of Surgery 2018; 35(4): 25-30
Novel techniques for lymphatic mapping have shown promising results which further simplify the procedure while improving the accuracy. Axillary reverse mapping, a technique to preserve lymph nodes draining the arm during axillary surgery for breast cancer has been described recently which has further reduced surgical morbidity. The omission of axillary surgery in selected patients with an acceptably low risk of nodal metastasis has gained increasing research interest in the recent past. Furthermore, advances in treatment and newer prognostication techniques have reduced the dependence on axillary nodal status on adjuvant therapy decision-making. This has led to several ongoing clinical trials which will assess the feasibility of avoiding sentinel lymph node biopsy altogether in selected groups of patients without compromising outcomes.

\section{Introduction}

Breast cancer is the most common female cancer worldwide including both developing and developed countries [1]. In Sri Lanka, breast cancer has become the commonest cancer and a continuous increase in the incidence is observed [1]. Treatment of breast cancer initially was based on management of primary cancer and the adjacent region; the breast and the axilla. This however has changed dramatically with the advent of systemic therapy which not only has led to major improvements in survival but also less radical surgery [2]. The role of surgery in the management of the axilla especially in patients with early-stage breast cancer has evolved in the past few decades with the improvement in the understanding of the disease together with advances in systemic therapy. This review focuses on the evolution of the surgical management of axilla in breast cancer and summarises the current evidence on sentinel lymph node biopsy (SLNB) in early breast cancer patients, novel techniques for SLNB, and the ongoing clinical trials on management of axilla in breast cancer.

\section{Evolution of breast cancer surgery}

The history of management of breast cancer goes back to early 1800s. Rudolf Virchow (1821-1902), a German pathologist postulated a hypothesis based on his autopsy studies that there was evidence of axillary lymph node (ALN) involvement in females who died from advanced disease[3]. Local invasion of cancer with progressive spread to regional 
and distant structures were key components of his hypothesis. Based on these findings, William Halsted (1852-1922) introduced radical mastectomy which comprised of a radical resection of breast with pectoralis major and minor muscles together with ALNs as en bloc [4]. David Patey in 1940s introduced modified radical mastectomy which preserved pectoralis major muscle to reduce surgical morbidity without compromising on overall survival [5]. Later, Madden and Auchincloss showed that the pectoralis minor muscle can also be preserved while achieving a ALN clearance with comparable outcomes [6]. With better understanding of the pathogenesis of the disease and advances of local and systemic adjuvant treatment, the concept of radical surgery was disputed and breast conservative surgery became the standard of care where feasible. The simple mastectomy was first developed by Kennedy and Miller [7]. In 1991, Toth and Lappert described skin sparing mastectomy which allowed breast reconstructions with improved cosmetic outcomes [8].

Management of ALNs has been a cornerstone in patients with breast cancer. It helps with regional disease control and provides valuable information for prognostication and for decisions on adjuvant therapy. Axillary lymph node dissection (ALND) remained as the method of axillary staging and routine ALND was the gold standard of managing the axilla until the 1970 s, despite the surgical morbidity related to the procedure. This practice started to change after the which National Surgical Adjuvant Breast and Bowel Project (NSABP) trial B-04 disputed the value of ALND in patient without any clinical evidence of axillary metastasis as approximately $40 \%$ of patients undergoing ALND had negative nodal involvement [9]. This proportion increased further with the introduction of mammographic breast cancer screening in 1980s, which led to a rise in early breast cancers. As a result, many researches were conducted to study the usefulness of ALND in such patients with early stage disease with no clinical involvement of the ALNs.

\section{Axillary staging with sentinel lymph node biopsy in breast cancer}

Axillary lymph node staging in patients with breast cancer is initially performed with physical examination of regional nodes. However, this is influenced by body habitus and thus has an approximately 50\% false-negative rate (FNR) [10]. Therefore, ultrasonography is the preferred modality for nodal assessment. Additional advantages of ultrasonography include the ability to obtain guided needle biopsies to allow pathological assessment of suspicious nodes. However, to date no imaging modality has been accurate enough to accurately stage the axilla especially when the nodal burden is minimal.

The concept of SLN is based on the principle of lymphatic drainage from the breast to regional lymph nodes which follows an orderly pattern initially reaching a node or few nodes known as the sentinel lymph nodes (SLN). Initial understanding of different sentinel node groups depending on the site of the tumour was challenged by the subsequent studies which showed that all lymph drains into the same sentinel nodes through the subareolar lymphatic plexus of Sappey [11]. Further studies have shown that periareolar or intradermal injections of mapping agents are equivalent or superior to peritumoural injections [12]. Although internal mammary nodes can drain the deep retromammary areas, the risk of involvement without axillary nodal involvement is minimal and hence isolated or initial internal mammary nodal recurrences remains very low [13].

SLNs are harvested using different techniques which commonly include a blue coloured dye (methylene blue or isosulphan blue) or a radioactive technetium 99m-labelled colloid. Detection rate for SLNs are approximately $90 \%$ with the blue dye and $>95 \%$ when combined with a radioactive tracer [14]. Novel techniques for detection of SLN include indocyanine green fluorescence, contrast-enhanced ultrasound using micro bubbles and superparamagnetic iron oxide nanoparticles which however are not widely practised yet. A recent systematic review has shown that these newer methods to be comparable to existing techniques in relation to detection rates [14].

\section{Management of clinically negative axilla}

Sentinel lymph node biopsy vs. axillary lymph node dissection for axillary staging

Due to the associated surgical morbidity, ALND was a major concern in patients with negative axillary nodes. NSABP B32 trial was conducted with the objectives of determining the value of SLNB in regional control and overall survival compared with ALND in resectable breast cancers with clinically negative axillae [15]. This randomized phase three multicentre clinical trial randomly assigned 5611 to SLNB plus ALND or SLNB alone with ALND only if sentinel nodes were positive. Identification of SLN was done with a combination of radiocolloid and isosulfan blue dye. SLN identification rate was $97.2 \%$ with a FNR of $9.8 \%$. After a median follow up of nearly 8 years no significant differences were observed in disease-free survival (hazard ratio [HR] $1.05, \mathrm{p}=0.54$ ) or overall survival (HR: $1.20, \mathrm{p}=0.12$ ) between the two groups. A substantial reduction in surgical morbidity was noted in SLNB alone group in terms of shoulder stiffness, lymphedema and upper limb numbness. Similar results were obtained from ALMANAC and Milan trials [16, 17]. Based on these studies, SLNB is currently considered as the standard of axillary staging in operable breast cancers with clinically negative axillae.

Positive Sentinel node biopsy - Sentinel node biopsy alone or axillary lymph node dissection?

Z0011 trial conducted by the American College of Surgeons 
Oncology Group assessed impact of avoiding ALND in patients with positive SNLs on local cancer recurrence and survival [18]. This phase three non-inferiority randomized control trial included breast cancer patients with clinically negative axilla with T1-T2 cancers undergoing lumpectomy and whole breast irradiation. Patients with 1-2 sentinel nodes positive for micro or macro metastasis were randomized into ALND or no further axillary surgery. There was no significant difference in 5-year overall survival and disease-free survival between the two groups after a median follow up of over 6 years. This land mark trial findings confirmed the safety of omitting ALND in T1 or T2 breast tumours with less than three positive SLNs. Furthermore, 10-year of follow up has confirmed the absence of a difference in outcomes between the two groups [19]. Two other randomized trials have evaluated patients with micro metastasis $(>0.2 \mathrm{~mm}$ but $\leq 2$ $\mathrm{mm}$ ), the IBCSG 23-01 trial (primary tumour $<5 \mathrm{~cm}$ ) and AATRM trial (primary tumour $<3.5 \mathrm{~cm}$ ) [20, 21]. Both showed no statistical significance in disease free survival [20, 21]. Thus, the place of ALND in those with locally advanced disease in $<3$ SNLs was disputed. Findings of these trials were incorporated into National Comprehensive Cancer Network (NCCN) Clinical Practice Guidelines in Oncology [22] and American Society for Clinical Oncology (ASCO) guidelines.

With the establishment of SLNB as the standard of care, fewer nodes were available for pathological analysis and hence, immunohistochemistry gradually gained popularity. However, this resulted in identification of isolated tumour cells, which is defined as clusters of metastatic deposits of 0.2 mm or less in size, single tumour cells or clusters of $<200$ cells in a single cross-section [23]. Several prospective trials have shown no differences in overall survival rates between immunohistochemistry positive and negative patients [24]. Thus, most current guidelines do not recommend the routine use of immunohistochemistry of SLNs [22]. However isolated tumour cells may be clinically relevant in lobular tumours due to their non-cohesive growth patterns [25]. Therefore, nodal metastases may present as widely dispersed isolated tumour cells [25]. Thus some still perform immunohistochemistry of SNLs in patients with lobular cancers and consider ALND when isolated tumour cells are identified [23].

\section{Axillary lymph node dissection vs. radiotherapy for positive lymph nodes}

In the instances where the decision has been taken to proceed with treatment of axilla due to positive SNLs, ALND is considered as the standard. However, this is associated with substantial long-term morbidity. After Mapping of the Axilla, Radiotherapy or Surgery (AMAROS) trial evaluated the place of axillary radiotherapy instead of ALND [26]. This multicentre randomised, phase three non-inferiority clinical trial included patients with $\mathrm{T} 1$ and $\mathrm{T} 2$ breast cancers with absent clinical lymphadenopathy and were randomized into
ALND or axillary radiotherapy. After a median follow up of over 6 years, comparable axillary control with less morbidity was observed in axillary radiotherapy group.

\section{Sentinel node biopsy in women older than 70 years}

Elderly patients over 70 years of age with clinical stage I (T1N0M0) and oestrogen receptor positive breast carcinoma have less aggressive course of disease. Studies have shown these patients to have no difference in mortality with no surgery for the axilla compared with ALND [27, 28]. The impact of avoiding radiotherapy in elderly patients undergoing breast conserving surgery was analysed in Cancer and Leukemia Group B 9343 trial. This trial randomized elderly women into radiotherapy with tamoxifen versus tamoxifen only. This study showed that adjuvant radiotherapy did not alter the local recurrence rates or survival of these patients who had oestrogen receptor positive early breast cancers [27]. However, this trial was conducted prior to the era of standard SLNB, and as a result $60 \%$ of the patients did not undergo axillary surgery. Therefore, these results could be biased due to the inclusion of patients into node negative group based on clinical evaluation alone. Some current guidelines including the Society of Surgical Oncology recommend the omission of routine SLNB in females over 70 years of age with hormone receptor positive and clinically negative axilla [29]. Furthermore, the latest NCCN guidelines recommend SLNB as optional in women older than 70 years with tumours with favourable prognostic characteristics, in whom axillary staging has no effect on the decisions regarding systemic adjuvant treatment [22].

\section{Place of sentinel node biopsy in patients undergoing neoadjuvant chemotherapy}

Neoadjuvant chemotherapy may be used in patients with clinically negative axilla at presentation due to unfavourable tumour biology, large primary tumour and patients' wish for breast conservative treatment. Although there is consensus that these patients should undergo SLNB, the timing of SLNB is controversial. Data from M.D. Anderson Cancer Centre have shown that comparable false negative rates $(5.9 \%$ vs. $4.1 \%$ in neoadjuvant and in surgery first group respectively, $p$ $=0.39$ ) with no significant differences in overall or disease free survival rates [30]. Interestingly, patients undergoing SLNB post-neoadjuvant chemotherapy showed significantly lower rates of positive SLNs in T1 to T3 tumour categories (T1 tumours: $12.7 \%$ vs. $19 \%, \mathrm{p}=0.2$; T2 tumours: $20.5 \%$ vs. $36.5 \%, \mathrm{p}<0.0001$; and T3 tumours: $30.4 \%$ vs. $51.4 \%$, $\mathrm{p}=0.04$ ). Dual tracer method with removal of two or more sentinel nodes are recommended to reduce the false negative rates associated with SNB after neoadjuvant therapy [30].

\section{Management of the clinically positive axilla}

Avoiding axillary surgery is beneficial to the patient due to its associated side effects, some of which carry a substantial morbidity. However, ALND is still considered as the routine 
standard for patients with clinical, radiologically or pathologically proven positive axillae. Furthermore, ALND is performed when SLNB fails or when it is contraindicated. Standard ALND which removes level I and II axillary lymph nodes preserving the axillary vein, thoracodorsal neurovascular pedicle, and the long thoracic nerve allows comprehensive staging of the axilla. Level III clearance is not performed routinely except in situations where level III nodes are clinically involved due to the excess risk of surgical morbidity.

Patients with axillary disease often receive neoadjuvant chemotherapy and with the advancement of efficacy of the agents, response to treatment has also improved with nodal eradication rates of approximately 40\% [31]. ACOSOGZ1071 (Alliance) prospective multicentre clinical trial revealed variable nodal conversion rates depending on the receptor status of the tumour [31]. Conversion rates were $21.1 \%$ for ER/PR positive, HER-2 negative tumours; $49.4 \%$ for triple negative tumours and $64.7 \%$ for HER-2 positive tumours. Usage of dual tracer technique and removal of three or more sentinel lymph nodes have shown to reduce FNR in this group of patients [3?]

Routine use of ALND in patients with clinically node negative axillae after neoadjuvant therapy has been brought to question as there was an increasingly higher complete pathological response rates in the axilla. Three large prospective registry studies have evaluated the role of SLNB followed by ALND after completion of neoadjuvant chemotherapy in clinically T1-4, N1-2, M0 breast cancers who received neoadjuvant chemotherapy [32-34]. Of these the ACOSOG-Z0171 trial evaluated the FNR of SLNB and reported a FNR of $12.6 \%(90 \% \mathrm{CI}=9.85 \%-16.05 \%)$. The use of dual tracers, harvesting three or more SLN and use of immunohistochemistry were shown to reduce the FNR substantially [32]. Furthermore, ultrasonography was shown to be highly unreliable in assessing the nodal response of neoadjuvant therapy. Of the 430 patients with negative nodes on ultrasonography after neoadjuvant chemotherapy, 243 $(56.5 \%)$ had residual positive nodes. Furthermore, 28.2\% (51/181) of patients with suspicious nodes on ultrasonography after neoadjuvant chemotherapy were found to be negative pathologically [35]. The SENTinel NeoAdjuvant (SENTINA) study which was a multicentre European trial showed similar findings in terms of FNR with an overall FNR of $14.2 \%$ [34]. However, in that trial only $25 \%$ underwent pathological confirmation of nodal disease before neoadjuvant chemotherapy.

The ACOSOG Z1071 studied the usefulness of placing a nodal clip in 170 patients with biopsy-proven nodal disease. In $75.9 \%$ patients with more than two SLNs retrieved, the clip was found to be inside the retrieved SLN with a FNR of $6.8 \%$ (95\% CI $=1.9 \%-16.5 \%$ ) [36]. Much higher FNRs were reported when a clip was not used or when the clip could not be retrieved during surgery (13.4\% and $14.3 \%$, respectively) [36]. Hence, retrieving the clipped node with previously confirmed disease, which may or may not be the SLN, is recommended to be added to surgical staging of axilla after neoadjuvant chemotherapy. Targeted axillary dissection is a newer technique which removes both the sentinel nodes and the clipped node, which would help minimize morbidity of ALND while maintaining an acceptability low FNR. Several current studies are evaluating the usefulness of targeted axillary dissection in comparison to the existing techniques[23].

There is still a controversy surrounding the management of pre-neoadjuvant node-positive patients who become node negative after neoadjuvant chemotherapy. At present, here is insufficient good quality data evaluating the oncological outcomes of excluding ALND in this group of patients. However, some are already practising SLNB instead of primary ALND for these patients [23].

\section{Minimizing morbidity of SNB/ALND - Axillary reverse mapping (ARM)}

ARM is the mapping of the arm and the breast lymphatic drainage systems simultaneously so that nodes draining the upper limb can be identified separately from the nodes that drain the breast [37]. This is performed with two different types of mapping agents injected simultaneously to the arm and the breast i.e. radioisotope to the breast and blue dye to the arm. With this technique, it is feasible to identify the lymphatics and nodes draining the upper limb and preserve them preserve them. However, the preservation of crossover nodes draining both the arm and the breast may result in suboptimal oncological lymph node clearances. A recently published meta-analysis has confirmed the feasibility of ARM and the significantly low rates of lymphedema associated with ARM compared with standard ALND [38]. However, further studies are needed to confirm the oncological safety of this technique before it could be incorporated in to standard practice.

\section{Future perspectives in the management of axilla in breast cancer}

Several prospective, multicentre, randomized controlled trials are in progress to address the above concerns in clinically node positive patients who receive neoadjuvant chemotherapy. NSABP B-51/Radiation Therapy Oncology Group 1304 Trial is an ongoing randomized phase three clinical trial including patients with $\mathrm{T} 1$ to T3, FNAC proven positive axillary nodes undergoing neoadjuvant chemotherapy [23]. Patients with clinically node negative axillae post neoadjuvant therapy are randomized to receive no nodal irradiation versus nodal irradiation. Outcomes of interest in this study include overall and disease-free survival and quality of life in irradiated versus non-irradiated patients [23]. 
Another ongoing randomized trial, the Alliance A11202 trial is studying the impact of avoiding routine regional nodal irradiation after ALND in patients with residual positive nodal disease after neoadjuvant chemotherapy [23]. The outcomes of interest of this study include overall and disease free survival and incidence of lymphedema in the two groups [23].

Future research will focus to identify patients who have low risk axillary nodal disease where surgery of the axilla can be avoided altogether. To this end, some preliminary studies have shown potential of gene expression profiling in predicting nodal involvement which may potentially help avoid axillary surgery.

\section{Conclusion}

The principles of surgical management of ALNs in breast cancer has undergone a major change from the initial radical surgery to minimally invasive and then to no surgery at all at least in some selected groups of patients. SLNB as the standard of care in patients with early breast cancer is well established, and the indications for ALND is becoming less and less due to associated surgical morbidity. Accurate evaluation of ALNs is important in decision making and clinicians should be aware of the pros and cons of various techniques of axillary staging. The role of SLNB after neoadjuvant therapy in clinically negative axilla is gradually being incorporated in practice. However, SLNB after neoadjuvant treatment in clinically positive axilla is still not well established as a routine due to the high FNR. Further studies will be useful to assess the role of SLNB after neoadjuvant chemotherapy in patients with clinically positive axillae. Current and future research focus on identifying patients with an acceptably low risk ALN metastasis where axillary surgery could be omitted.

All authors disclose no conflict of interest. The study was conducted in accordance with the ethical standards of the relevant institutional or national ethics committee and the Helsinki Declaration of 1975, as revised in 2000 .

\section{References}

1. Fernando A, Jayarajah U, Prabashani S, Fernando EA, Seneviratne $S$ A. Incidence trends and patterns of breast cancer in Sri Lanka: an analysis of the national cancer database. BMC Cancer. 2018;18(1):482.

https://doi.org/10.1186/s12885-018-4408-4

2. Kesson EM, Allardice GM, George WD, Burns HJ, Morrison DS. Effects of multidisciplinary team working on breast cancer survival: retrospective, comparative, interventional cohort study of 13722 women. BMJ. 2012;344:e2718.

https://doi.org/10.1136/bmj.e2718

3. Virchow R, Chance F. Cellular Pathology as based upon physiological and pathological histology. Twenty lectures delivered in... 1858. Translated from the second edition of the original by F. Chance. With notes and numerous emendations principally from MS. notes of the author, and illustrated by... engravings on wood 1860 .
4. Halsted WS. I. The results of operations for the cure of cancer of the breast performed at the Johns Hopkins Hospital from June, 1889, to January, 1894. Ann Surg. 1894;20(5):497. https://doi.org/10.1097/00000658-189407000-00075

5. Patey D, Dyson W. The prognosis of carcinoma of the breast in relation to the type of operation performed. $\mathrm{Br} \mathrm{J}$ Cancer. 1948;2(1):7. https://doi.org/10.1038/bjc.1948.2

6. Auchincloss H. Modified radical mastectomy: why not? The American Journal of Surgery. 1970;119(5):506-9. https://doi.org/10.1016/0002-9610(70)90163-7

7. Kennedy CS, Miller E. Simple mastectomy for mammary carcinoma. Ann Surg. 1963;157:161.

8. Toth BA, Lappert P. Modified skin incisions for mastectomy: the need for plastic surgical input in preoperative planning. Plast Reconstr Surg. 1991;87(6):1048-53. https://doi.org/10.1097/00006534-199106000-00006

9. Rastogi P, Wickerham DL, Geyer Jr CE, Mamounas EP, Julian TB, Wolmark N. Milestone clinical trials of the National Surgical Adjuvant Breast and Bowel Project (NSABP). Chinese clinical oncology. 2017;6(1):7. https://doi.org/10.21037/cco.2017.02.02

10. Sacre R. Clinical evaluation of axillar lymph nodes compared to surgical and pathological findings. European journal of surgical oncology: the journal of the European Society of Surgical Oncology and the British Association of Surgical Oncology. 1986;12(2):169-73.

11. Tanis PJ, Nieweg OE, Olmos RAV, Kroon BB. Anatomy and physiology of lymphatic drainage of the breast from the perspective of sentinel node biopsy1. J Am Coll Surg. 2001;192(3):399-409. https://doi.org/10.1016/S1072-7515(00)00776-6

12. Povoski SP, Olsen JO, Young DC, Clarke J, Burak WE, Walker MJ, Carson WE, Yee LD, Agnese DM, Pozderac RV. Prospective randomized clinical trial comparing intradermal, intraparenchymal, and subareolar injection routes for sentinel lymph node mapping and biopsy in breast cancer. Ann Surg Oncol. 2006;13(11):1412-21.

https://doi.org/10.1245/s10434-006-9022-Z

13. Tanis P, Nieweg O, Olmos RV, Peterse J, Rutgers ET, Hoefnagel C, Kroon B. Impact of non-axillary sentinel node biopsy on staging and treatment of breast cancer patients. Br J Cancer. 2002;87(7):705. https://doi.org/10.1038/sj.bjc.6600359

14. Ahmed M, Purushotham AD, Douek M. Novel techniques for sentinel lymph node biopsy in breast cancer: a systematic review. The Lancet Oncology. 2014;15(8):e351-e62. https://doi.org/10.1016/S1470-2045(13)70590-4

15. Krag DN, Anderson SJ, Julian TB, Brown AM, Harlow SP, Ashikaga T, Weaver DL, Miller BJ, Jalovec LM, Frazier TG. Technical outcomes of sentinel-lymph-node resection and conventional axillary-lymph-node dissection in patients with clinically node-negative breast cancer: results from the NSABP B-32 randomised phase III trial. The lancet oncology. 2007;8(10):881-8. https://doi.org/10.1016/S1470-2045(07)70278-4

16. Mansel RE, Fallowfield L, Kissin M, Goyal A, Newcombe RG, Dixon JM, Yiangou C, Horgan K, Bundred N, Monypenny I. Randomized multicenter trial of sentinel node biopsy versus standard axillary treatment in operable breast cancer: the ALMANAC Trial. J Natl Cancer Inst. 2006;98(9):599-609. https://doi.org/10.1093/jnci/djj158

17. Veronesi U, Viale G, Paganelli G, Zurrida S, Luini A, Galimberti V, Veronesi P, Intra M, Maisonneuve P, Zucca F. Sentinel lymph node biopsy in breast cancer: ten-year results of a randomized controlled study. Ann Surg. 2010;251(4):595-600. https://doi.org/10.1097/SLA.0b013e3181c0e92a 
18. Caudle AS, Hunt KK, Tucker SL, Hoffman K, Gainer SM, Lucci A, Kuerer HM, Meric-Bernstam F, Shah R, Babiera GV. American College of Surgeons Oncology Group (ACOSOG) Z0011: impact on surgeon practice patterns. Ann Surg Oncol. 2012;19(10):3144-51.

https://doi.org/10.1245/s10434-012-2531-z

19. Giuliano AE, Ballman KV, McCall L, Beitsch PD, Brennan MB, Kelemen PR, Ollila DW, Hansen NM, Whitworth PW, Blumencranz PW. Effect of axillary dissection vs no axillary dissection on 10-year overall survival among women with invasive breast cancer and sentinel node metastasis: the ACOSOG Z0011 (Alliance) randomized clinical trial. JAMA. 2017;318(10):918-26.

https://doi.org/10.1001/jama.2017.11470

20. Galimberti V, Cole BF, Zurrida S, Viale G, Luini A, Veronesi P, Baratella P, Chifu C, Sargenti M, Intra M. Axillary dissection versus no axillary dissection in patients with sentinel-node micrometastases (IBCSG 23-01): a phase 3 randomised controlled trial. The lancet oncology. 2013;14(4):297-305. https://doi.org/10.1016/S1470-2045(13)70035-4

21. Solá M, Alberro JA, Fraile M, Santesteban P, Ramos M, Fabregas R, Moral A, Ballester B, Vidal S. Complete axillary lymph node dissection versus clinical follow-up in breast cancer patients with sentinel node micrometastasis: final results from the multicenter clinical trial AATRM 048/13/2000. Ann Surg Oncol. 2013;20(1):120-7.

https://doi.org/10.1245/s10434-012-2569-y

22. National Comprehensive Cancer Network (NCCN) Clinical Practice Guidelines in Oncology: Breast, Version 2017. Available at: http://www.nccn.org/. Accessed August 22, 2018.

23. Park KU, Caudle A. Management of the Axilla in the Patient with Breast Cancer. Surg Clin North Am. 2018.

https://doi.org/10.1016/j.suc.2018.04.001

24. Giuliano AE, Hawes D, Ballman KV, Whitworth PW, Blumencranz PW, Reintgen DS, Morrow M, Leitch AM, Hunt KK, McCall LM, Abati A, Cote R. Association of occult metastases in sentinel lymph nodes and bone marrow with survival among women with early-stage invasive breast cancer. JAMA. 2011;306(4):385-93.

https://doi.org/10.1001/jama.2011.1034

25. Mittendorf EA, Sahin AA, Tucker SL, Meric-Bernstam F, Yi M, Nayeemuddin KM, Babiera GV, Ross MI, Feig BW, Kuerer HM, Hunt KK. Lymphovascular Invasion and Lobular Histology are Associated with Increased Incidence of Isolated Tumor Cells in Sentinel Lymph Nodes from Early-Stage Breast Cancer Patients. Ann Surg Oncol. 2008;15(12):3369-77.

https://doi.org/10.1245/s10434-008-0153-2

26. Donker M, van Tienhoven G, Straver ME, Meijnen P, van de Velde CJ, Mansel RE, Cataliotti L, Westenberg AH, Klinkenbijl $\mathrm{JH}$, Orzalesi L. Radiotherapy or surgery of the axilla after a positive sentinel node in breast cancer (EORTC 10981-22023 AMAROS): a randomised, multicentre, open-label, phase 3 noninferiority trial. The lancet oncology. 2014;15(12):1303-10. https://doi.org/10.1016/S1470-2045(14)70460-7

27. Hughes KS, Schnaper LA, Bellon JR, Cirrincione CT, Berry DA, McCormick B, Muss HB, Smith BL, Hudis CA, Winer EP. Lumpectomy plus tamoxifen with or without irradiation in women age 70 years or older with early breast cancer: long-term follow-up of CALGB 9343. J Clin Oncol. 2013;31(19):2382. https://doi.org/10.1200/JCO.2012.45.2615

28. Martelli G, Boracchi P, Ardoino I, Lozza L, Bohm S, Vetrella G, Agresti R. Axillary dissection versus no axillary dissection in older patients with T1N0 breast cancer: 15-year results of a randomized controlled trial. Ann Surg. 2012;256(6):920-4. https://doi.org/10.1097/SLA.0b013e31827660a8
29. Landercasper J, Bailey L, Berry TS, Buras RR, Degnim AC, Fayanju OM, Froman J, Gass J, Greenberg C, Mautner SK. Measures of Appropriateness and Value for Breast Surgeons and Their Patients: The American Society of Breast Surgeons Choosing Wisely ${ }^{\circledR}$ Initiative. Ann Surg Oncol. 2016;23(10):3112-8.

https://doi.org/10.1245/s10434-016-5327-8

30. Hunt KK, Yi M, Mittendorf EA, Guerrero C, Babiera GV, Bedrosian I, Hwang RF, Kuerer HM, Ross MI, Meric-Bernstam F. Sentinel lymph node surgery after neoadjuvant chemotherapy is accurate and reduces the need for axillary dissection in breast cancer patients. Ann Surg. 2009;250(4):558-66.

https://doi.org/10.1097/SLA.0b013e3181b8fd5e

31. Boughey JC, McCall LM, Ballman KV, Mittendorf EA, Ahrendt GM, Wilke LG, Taback B, Leitch AM, Flippo-Morton T, Hunt KK. Tumor biology correlates with rates of breast-conserving surgery and pathologic complete response after neoadjuvant chemotherapy for breast cancer: findings from the ACOSOG Z1071 (Alliance) Prospective Multicenter Clinical Trial. Ann Surg. 2014;260(4):608. https://doi.org/10.1097/SLA.0000000000000924

32. Boughey JC, Suman VJ, Mittendorf EA, Ahrendt GM, Wilke LG, Taback B, Leitch AM, Kuerer HM, Bowling M, Flippo-Morton TS. Sentinel lymph node surgery after neoadjuvant chemotherapy in patients with node-positive breast cancer: the ACOSOG Z1071 (Alliance) clinical trial. JAMA. 2013;310(14):1455-61. https://doi.org/10.1001/jama.2013.278932

33. Boileau J-F, Poirier B, Basik M, Holloway CMB, Gaboury L, Sideris L, Meterissian S, Arnaout A, Brackstone M, McCready DR, Karp SE, Trop I, Lisbona A, Wright FC, Younan RJ, Provencher L, Patocskai E, Omeroglu A, Robidoux A. Sentinel Node Biopsy After Neoadjuvant Chemotherapy in BiopsyProven Node-Positive Breast Cancer: The SN FNAC Study. J Clin Oncol. 2015;33(3):258-64.

https://doi.org/10.1200/JCO.2014.55.7827

34. Kuehn T, Bauerfeind I, Fehm T, Fleige B, Hausschild M, Helms G, Lebeau A, Liedtke C, Minckwitz Gv, Nekljudova V, Schmatloch S, Schrenk P, Staebler A, Untch M. Sentinel-lymphnode biopsy in patients with breast cancer before and after neoadjuvant chemotherapy (SENTINA): a prospective, multicentre cohort study. The Lancet Oncology. 2013;14(7):60918. https://doi.org/10.1016/S1470-2045(13)70166-9

35. Boughey JC, Ballman KV, Hunt KK, McCall LM, Mittendorf EA, Ahrendt GM, Wilke LG, Le-Petross HT. Axillary ultrasound after neoadjuvant chemotherapy and its impact on sentinel lymph node surgery: results from the American College of Surgeons Oncology Group Z1071 Trial (Alliance). J Clin Oncol. 2015;33(30):3386. https://doi.org/10.1200/JCO.2014.57.8401

36. Boughey JC, Ballman KV, Le-Petross HT, McCall LM, Mittendorf EA, Ahrendt GM, Wilke LG, Taback B, Feliberti EC, Hunt KK. Identification and Resection of Clipped Node Decreases the False-negative Rate of Sentinel Lymph Node Surgery in Patients Presenting With Node-positive Breast Cancer (T0-T4, N1-N2) Who Receive Neoadjuvant Chemotherapy: Results From ACOSOG Z1071 (Alliance). Ann Surg. 2016;263(4):802-7. https://doi.org/10.1097/SLA.0000000000001375

37. Thompson M, Korourian S, Henry-Tillman R, Adkins L, Mumford S, Westbrook KC, Klimberg VS. Axillary reverse mapping (ARM): a new concept to identify and enhance lymphatic preservation. Annals of surgical oncology. 2007;14(6):1890. https://doi.org/10.1245/s10434-007-9412-x

38. Ahmed M, Rubio I, Kovacs T, Klimberg V, Douek M. Systematic review of axillary reverse mapping in breast cancer. British Journal of Surgery. 2016;103(3):170-8. https://doi.org/10.1002/bjs.10041 